\title{
TWO AUTOSOMAL RECESSIVE NEUROMUSCULAR DISORDERS - FRDA AND LGMD2A, IN A SINGLE BULGARIAN PEDIGREE
}

\author{
${ }^{1,2}$ Savina Tincheva, ${ }^{1,2}$ Albena Todorova, ${ }^{2}$ Tihomir Todorov, ${ }^{1}$ Vanyo Mitev \\ ${ }^{1}$ Department of Medical Chemistry and Biochemistry, Medical University of Sofia, \\ ${ }^{2}$ Genetic-Medico Diagnostic Laboratory "Genica”, Sofia
}

\begin{abstract}
Here we report a single pedigree affected by two different recessive neuromuscular disorders, namely Friedreich ataxia (FRDA) and Limb-Girdle Muscular Dystrophy Type 2A (LGMD2A). The molecular genetic testing showed that in this family FRDA is caused by an expanded GAA repeat in compound heterozygous state with a novel point mutation c.442C $>\mathrm{T}$, p.Gln148* on the other allele of the $F X N$ gene. This case of two siblings (16 years old male and 18 years old female) is the first report of Bulgarian FRDA case carrying a point mutation in the FXN gene. The LGMD2A affected individual (second cousin of the FRDA affected patients) was found to be compound heterozygous for the two most common CAPN3 mutations for the Bulgarian population (c.550delA, p.Thr184Argfs; c.967G >T, p.Glu323*). To the best of our knowledge we are reporting the first Bulgarian family with two neurological disorders caused by mutations in genes on different chromosomes and segregating independently in the family. This single pedigree with four different mutations in two different genes (in both disorders due to compound heterozygosity) is an example for the high genetic heterogeneity of the Bulgarian population.
\end{abstract}

Keywords: CAPN3 gene, Friedreich ataxia, FXN gene, Limb-Girdle Muscular Dystrophy Type 2A, Single pedigree

\section{INTRODUCTION}

Friedreich ataxia (FRDA, MIM 229300) is an autosomal recessive form of ataxia characterized mainly by dysarthria, muscle weakness and spasticity in the lower limbs. It is a progressive disorder of

Address for correspondence:

Savina Tincheva

Genetic-Medico Diagnostic Laboratory "Genica",

90 "Tsar Asen" Str., 1463, Sofia, Bulgaria.

Tel.: +359878 215 901;

fax: +359 295307 15;

e-mail:savina.tincheva@gmail.com

Received: August 2, 2015

Accepted: September 28, 2015 the nervous system with usual onset before the end of puberty (1). FRDA is caused by mutations in the FXN gene (MIM 606829) which is localized at 9q21.11. Typically, the disorder is associated with an unstable GAA trinucleotide expansion in intron 1. Homozygous expansion accounts for $98 \%$ of the cases of FRDA. However, about $2 \%$ of the FRDA patients are compound heterozygous for the expansion and a point mutation in the FXN gene (2).

Limb-Girdle Muscular Dystrophy Type 2A (LGMD2A, MIM 253600; Calpainopathy) is another autosomal recessive neuromuscular disorder presented with progressive proximal (limb-girdle) muscle weakness. The onset and phenotype show significant variability between the different families and the different individuals in the same family. Calpain- 
opathy is caused by mutations in the CAPN3 gene (MIM 114240) localized at 15q15.1 (3).

\section{CASE PRESENTATION}

Here we present a family with two FRDA affected children - a male, 16 years old at the moment of the genetic testing and still ambulant but with severe difficulties in walking, and female, 18 years old and already wheel-chair bounded. Both children present with typical clinical manifestations with an onset before puberty. The first symptoms included poor walking balance and slurred speech. With the progression of the disease the patients experienced dysarthria and muscle weakness in hip extensors and abductors, followed by distal limb muscle weakness and wasting. Spasticity in the lower limbs became prominent.

It is interesting to note that in the same family there is also another genetically verified autosomal recessive neuromuscular disorder - LGMD2A. Figure 1 illustrates the pedigree of the family we have examined. The FRDA affected individuals (IV-1 and IV-2) and the LGMD2A affected patient (IV-5) are second cousins. The IV-5 patient is a 15 years old female at the time when the genetic analysis was performed with typical clinical presentation of LGMD2A: proximal weakness, weakness in the upper limb and the shoulder girdle, severe contractures and spine deformities.

Our study started from a healthy relative of the presented patients (female, 31 years old; IV-3), in the context of genetic counseling. She is a first cousin of the FRDA affected (IV-1, IV-2) and second cousin of the LGMD2A affected (IV-5) family members. The individuals affected by FRDA (IV-1, IV-2) and by LGMD2A (IV-5) are part of an extended pedigree, but originate from two different nuclear families without any consanguinity.

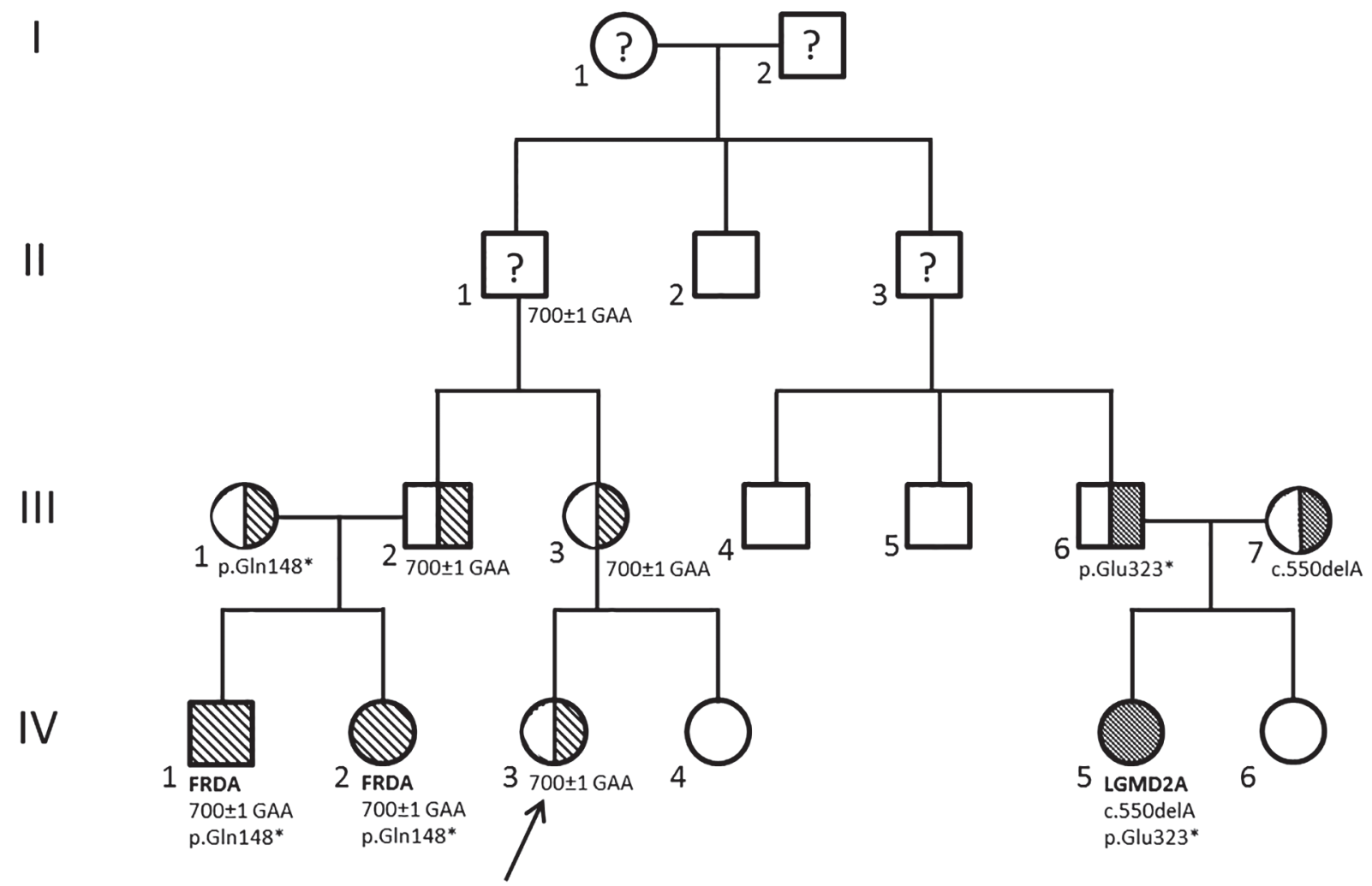

Fig. 1. Family pedigree; squares indicate males; circles - females; open symbols represent normal subjects; striped symbols - FRDA affected individuals; semistriped symbols - FRDA carriers; dotted symbols - LGMD2A affected individuals; semidotted symbols - LGMD2A carriers; the individuals with unknown genotype are marked by a question mark.

The consulting individual is marked by an arrow 


\section{METHODS}

Mutation analysis of the FXN and CAPN3 gene was performed. Primers were designed to specifically amplify all exons and intron/exon boundaries. Direct sequencing of the amplified products was performed using BigDye Terminator v3.1 Cycle Sequencing Kit (Applied Biosystems, Foster city, CA) in order to detect point mutations. The GAA repeat expansion was detected by short PCR for identification of normal and TP-PCR for identification of expanded alleles. Normal alleles in healthy controls contain 5-60 GAA repeats. In Friedreich's Ataxia patients, the GAA repeat varies from 66 to 1700 .

\section{RESULTS AND DISCUSSION}

Both FRDA affected patients (IV-1, IV-2) are carrying a GAA expansion in compound heterozygous state with a nonsense mutation c.442C $>\mathrm{T}$, p.Gln148*. The female (IV-2) has been tested by Southern blot (through foreign collaboration) revealing a size of the expansion of about $700 \pm 1$ GAA repeats. Molecular genetic testing of the male sibling was executed only by TP-PCR to confirm the expanded allele ( $>66$ GAA repeats), although not giving the possibility to determine the exact size of the expansion. Only $2 \%$ of the FRDA patients are compound heterozygous for the expansion and a point mutation in this gene (2). To the best of our knowledge this is the first FRDA case in Bulgaria with a point mutation in the FXN gene. Moreover, the detected nonsense change c. $442 \mathrm{C}>\mathrm{T}$, p.Gln $148^{\star}$ has not been previously reported.

The molecular genetic testing of the LGMD2A patient (IV-5) showed that she was compound heterozygous for two severe inactivating mutations in the CAPN3 gene: c.550delA, p.Thr184Argfs in exon 4 transmitted by the mother (III-7) and c.967G $>\mathrm{T}$, p.Glu $323^{*}$ in exon 7 inherited from the father (III-6). These two mutations are the most common for the Bulgarian population (4).

The consulting individual has been tested for the family mutations in both FXN and CAPN3 gene. The molecular genetic testing showed that she is an asymptomatic carrier of the GAA expansion in the FXN gene (detected trough TP-PCR). Fortunately none of the familial mutations in the CAPN3 gene were inherited by her. From the genotype of the index patient and this of patients IV-1, IV-2 (carrying the GAA expansion) we can conclude that both the mother of the consulting female and the father of the FRDA patients (they are siblings) are carriers of the GAA expansion (although not tested as they are not willing to be part of the present study). The affected LGMD2A patient IV-5 turned out to be negative for the GAA expansion. Therefore, we cannot conclude if II- 1 and II- 3 have carried the GAA expansion in the FXN gene together with the familial p.Glu323* mutation in the CAPN3 gene and whether these two genetic defects originate from a single parental pair (I-1 and I-2). Unfortunately, it is not possible to follow further these two pathologies within the pedigree.

Worldwide there are very few reported cases with more than one rare genetic disorder in the same pedigree. In the Bulgarian population there has been found a family with three genetic disorders Fragile X syndrome (FraX, MIM 300624), Duchene muscular dystrophy (DMD, MIM 310200) and X-linked ichthyosis (XLI, MIM 308100), but all of them caused by defects affecting loci on the X chromosome (5). Previously there has been described one Bulgarian case of an extended pedigree with two rare genetic disoders (6).

To the best of our knowledge we are reporting the first Bulgarian family with two neurological disorders caused by mutations in genes on different chromosomes and segregating independently in the family. Both neurological disorders presented in our family are rare with a prevalence of about 1:29 000 (7) for FRDA and 1:100 000 for calpainopathy (8), with only 24 cases of calpainopathy in Bulgaria (9). Here, both pathologies are caused by compound heterozygous mutations and not by homozygous mutations resulting from consanguineous marriages. The presence of four different protein truncating mutations in a single family is an example of the high genetic heterogeneity of the Bulgarian population.

\section{REFERENCES}

1. Friedreich N (1863). "Ueber degenerative Atrophie der spinalen Hinterstränge”. Arch Pathol Anat Phys Klin Med 26 (3-4): 391-419. doi:10.1007/ BF01930976.

2. Campuzano V, Montermini L, Molto MD, et al. Friedreich's ataxia: autosomal recessive disease caused by an intronic GAA triplet repeat expansion. Science. 1996;271:1423-1427. 
3. Beckmann JS, Richard I, Hillaire D, Broux O, Antignac C, Bois E, Cann $\mathrm{H}$ et al. A gene for limb-girdle muscular dystrophy maps to chromosome 15 by linkage analysis. C RAcad Sci III, 312 (1991), pp. 141-148.

4. Todorova A, Georgieva B, Tournev I et. al. A large deletion and novel point mutations in the calpain 3 gene (CAPN3) in Bulgarian LGMD2A patients. Neurogenetics. 2007 Aug;8(3):225-9.

5. Todorova A, Litvinenko I, Todorov T, Tincheva R, Avdjieva D, Tincheva S, Mitev V. A family with fragile X syndrome, Duchenne muscular dystrophy and ichthyosis transmitted by an asymptomatic carrier. Clin Genet. 2014 Mar;85(3):286-9.

6. Ангелова Л, Стоянова М, Гаданчева В, Стоянов В, Тинчева Р, Димитров Б. Туберозна склероза и ганглиозидоза- $\mathrm{Gml}$ в рамките на едно семейство. (2011) II Национална конференция по редки болести, Пловдив.

7. Hurst JA, Firth HV, Hall JG. Oxford Desk Reference Clinical Genetics (2013).

8. http://www.medscape.com/

9. Тончева Д. Редки генетични болести, Том 1, София (2014). 